\title{
A Reality in Question: Negotiating Realism and Storyworld Construction in James Ward Byrkit's Coherence
}

\author{
Valtteri Leinonen, Comparative Literature*
}

\begin{abstract}
This paper examines how the film Coherence (2013), directed by James Ward Byrkit, challenges foundational conceptions of its diegetic reality as held by the film's viewer. The discussion centers around a cognitive narratological analysis of the events that help define the storyworld constructed for the film. Included in the analysis is consideration of Coherence's realist aesthetic which is used as a contrasting plane to the film's unfurling science-fiction premise of parallel universes. It is posited that realism is a mode which can be applied in a variety of ways, regardless of a film's genre, subject matter, or sociopolitical motivation. In Coherence's case, the mode is used to complicate storyworld construction for the viewer and thus engage him/her more closely in the viewing experience. The paper's principal contention involves cognitive frame systems which the viewer uses to process Coherence's diegetic reality. By negotiating opposing theories of Manfred Jahn and Marina Grishakova, the paper argues for a frame system which is defined by a single primary frame, allows multiple conflicting frames, and is generally respectful of the comprehension needs of a narrative. Agreement in frame systems and the basics of narrative comprehension, it is concluded, grounds interpretation and discussion of film altogether in a necessary way.
\end{abstract}

\section{INTRODUCTION}

In James Ward Byrkit's Coherence (2013), a group of middle-aged friends gathered for a dinner party are forced to deal with an inexplicable phenomenon of parallel universes appearing to intersect. With the amount of affirming evidence and strange occurrences increasing, the group goes about figuring out the nature of the phenomenon in unison. This paper looks at the way Coherence draws its viewer into a comparable state of speculation and eventually into revising his/her understanding of the diegetic reality - the fictional world presented by the narrative.

The two opening sections of the paper serve to establish the key discursive threads to follow. The first section investigates how Coherence, even though a science-fiction film, relates to the category of realism through its aesthetic approach. At its most concise, realism in film strives for a "direct and truthful view of the real world" (Hayward 298; Konigsberg 285). The establishing contention is that Coherence is disinterested in presenting such a view but still utilizes a realist

*Valtteri Leinonen has been studying at the University of Oregon as an exchange student for Fall Term 2014. For the rest of the school year, he returns to his native Finland to complete his bachelor's degree in Comparative Literature at the University of Tampere. He is considering applying to graduate school to study film. Please direct correspondence to leinonen.valtteri.e@student.uta.fi. 
aesthetic of its own. The second section introduces the cognitive method used later in an analysis of Coherence's narrative structure. Adapted from Menakhem Perry's literary dynamics, the method involves speculation of hypotheses and basic mental models - frames, which bundle and explain information - constructed based on narrative events.

The following two sections, in turn, are built around said analysis. The analysis focuses on the narrative events which most forcefully prompt a re-evaluation of the diegetic reality, a change in storyworld. Storyworld refers to the viewer's attempt to explain the nature of the diegetic reality with a cognitive frame as effectively as possible. Coherence complicates storyworld construction with its emerging, parallel universes. To comprehend the film, the viewer is even required to form two conflicting storyworld frames at once, a "reality frame" and a "supernatural frame." Interwoven with this analysis will be discussion of the realist aesthetic and its role in storyworld construction. On the matter, this paper posits in culmination that realism is a mode which can be evoked regardless of a film's subject matter or degree of social involvement. Coherence is exemplary of the mode's unrestricted possibilities: its realist aesthetic tries above all to engage the viewer's cognitive processing, rather than enforce a "truthful view" of any kind.

The paper's main theoretical conclusion will be explored in the fifth and final section. Based on processing a challenging storyworld like Coherence's, it is argued that a flexible frame system is needed - one that allows conflicting frames and adheres to the comprehension needs of a given narrative. A frame system describes the manner with which frames exist and relate to one another in the viewer's mind. Frame systems proposed by Manfred Jahn and Marina Grishakova will be introduced in the analysis sections and negotiated in the final section. The negotiation and subsequent conclusion strive to ground interpretation in general, as it is in essence built on narrative comprehension and related cognitive processing.

\section{CONTENDING A REALIST AESTHETIC FOR A FUNHOUSE FILM}

Associating Coherence with realism might seem grossly counterintuitive. Best described as an independently produced science-fiction mystery, the film's mere genre tag seems to suggest an indifference to depicting the material reality as it is. According to Ira Konigsberg, representations of the material reality, the outside "real world" (Konigsberg 285), should "heighten... consciousness" (285) and explore social problems (286). These are some basic tenets of realism in film, and they largely do not align with the specific aims of Coherence that are shaped by the film's genre. With a mystery story comparable to a "funhouse" (Tobias) in the words of its director James Ward Byrkit, Coherence fits neatly into the relatively recent wave of low-budget American science-fiction films. These films include titles such as Shane Carruth's Primer (2004) and Upstream Color (2013) as well as Mike Cahill's Another Earth (2011). Applicable to all the films in question are Byrkit's production goals of "making the most of simple locations" and "giving a very cosmic feeling to the most mundane circumstances" (Tobias). Inspiration for the goals and Coherence's story is assumed in particular from the classic sci-fi television series The Twilight Zone (1959-1964) (Tobias). In their foundation of simple locations and mundanity, the production goals do in fact approach a kind of utilitarian relation with the material reality. Indeed, by taking a closer look at Coherence's production history, it may become apparent as to why a designation 
of realism, or at least one that describes the surface-level of film style, might be relevant in discussing the film.

Coherence was conceived by Byrkit and his creative partner Alex Manugian with an improvisational concept in mind. The film was to be shot with a small crew and in sequence over five days at Byrkit's house. Its cast of eight actors (minus Manugian who plays the character of Amir) was not made aware beforehand of the plot's carefully thought-out trajectory involving alternative universes. Instead, the actors were prompted to react to their surroundings and to each other with only an outlined knowledge of individual character motivations (Tobias). Of shooting with such an unconventional approach, Byrkit has said:

You're improvising along with the actors as a director, and cameraman. My DP, Nic Sadler, and I told them, "You can go anywhere you want in the house and we'll follow you. We're not going to rehearse it or block it." We just treated it almost like a documentary unfolding in front of us. (Lattanzio)

The improvisational concept described by Byrkit suggests an accentuated presence of the film crew in the middle of the filmed action. Such a presence has a stake in Coherence's realist aesthetic which will be outlined in this section by means of close watching a scene from the film.

Before advancing to the stylistic analysis of Coherence, however, it is necessary to cover better the theoretical foundations regarding realism in film. This means referring to the widely influential 1945 essay “The Ontology of the Photographic Image” by André Bazin. In his essay, Bazin confluences the mediums of photography and film, as they are related by overlapping histories of technology and innovative thought. Bazin claims that together the mediums "satisfy, once and for all and in its very essence, our obsession with realism" (What is Cinema 12). According to Bazin, it is the automatic production method which affords photography an unparalleled credibility compared to other visual arts. Free from subjective human intervention, "we are forced to accept as real the existence of the object reproduced" (13). Cinema repeats the same act of undeniable reproduction but, unlike photography, does it spanning time (14). Here, regardless of the language inclusive of the observing subject ("our obsession" and "we are forced to accept," respectively), Bazin accounts realism to be an inherent quality of the image itself.

In another essay, Bazin makes it a point for his theory to accommodate technological advancement, venturing that each new development takes film closer to its realist ideal (21). In fact, he wrote "Ontology" only a few years after the popularization of one such development, that of deep focus photography in Orson Welles' Citizen Kane (1941). To Bazin, the comprehensive clarity Welles brought to his shots "restored to reality its visible continuity" (Italian Neorealism 40). The implicit accomplice to depth of focus, in Bazin's eyes, is the long take (What is Cinema 34). The "long" in long take refers to the unusual temporal length of a shot; it is the result of refusing to disturb filmed action by cutting (34). When these means are taken together, Bazin's ideal of realism amounts to presenting spatiotemporal continuity in the most untampered manner possible - fluid action without patent manipulation of time and space. The lack of guidance in this type of realist presentation, Bazin further argues, encourages pronounced and more independent mental activity on the viewer's part when deriving meaning from film (35-36). 
Coherence frequently guides the viewer and plays with spatiotemporal continuity, but I argue that it also evokes a realist mode. To better understand how the film does that, the following takes a closer look at the first few shots of the film's second scene. I take Coherence to establish many of its key realist means early on and to subsequently enforce them throughout its running time even when the film's science-fiction premise eventually reveals itself.

To synopsize Coherence's "funhouse" story briefly: The film depicts four couples having dinner together during the night of a prominent comet sighting. Slowly the night escalates into a series of strange, supernatural occurrences. The occurrences cause the characters to fearfully remain at the house where the dinner party is held, or nearby it, as they try to make sense of what exactly is happening. The film's second scene is set in the kitchen of the main house, before anything truly supernatural has occurred. The scene opens with a close view of a canister of olive oil, an extreme close-up. The shot already displays a constant tinge of movement afforded by handheld camerawork. Both close-ups and the handheld camera are omnipresent in Coherence, providing the film an aesthetic signature. Both also enforce the realist mode, as later will be argued. The following shot cuts to yet another extreme close-up, this time of one of the present characters, Beth. Shot at a near right angle, the left side of the character's face defines the frame briefly but emphatically. Coinciding with the image of Beth, there is another character, Lee, asking pointedly in the shot's background, "See how you're slipping?" The words are not directed at Beth though, as the proceeding reorientation of the camera's interest displays. To start, there is a slow horizontal turning of the camera, a pan, to the left which casts Beth to the right edge of the frame. Then, there is an equally slow adjustment of lens focus, a rack, which brings forth into clarity a figure now defining the image, Mike. Via the one-two of the panning and the racking, attention is guided from Beth to Mike in a single shot without cutting needed. The camera manipulation imparts a fluidity to the action while still being very controlling of the viewer's gaze.

The two shots that follow are once again associated with food and involve Mike asking Beth about her new diet. The shots are also close-ups which mean the scene continues to withhold information about the real physical space it utilizes, the kitchen space existing in the material reality. The exact dimensions of the kitchen and the characters' placement within it are not made known until a medium shot from the waist up establishes spatial relations for the first time. In the medium shot, the inquisitive Mike is placed on the left side of the frame facing Beth who occupies the right. As Beth starts to answer him, Mike suddenly exits his side of the frame. Once off-frame, Mike gives a garbled response which, to further muddle the conversation, is instantly cut off by Beth. This kind of overlapping dialogue is very prevalent in Coherence and a symptom of what Byrkit calls "naturalistic performances" (Tobias). But as Byrkit indicates in the prior quoted passage, when the cast is acting and reacting in such a free manner, the crew has to follow suit. Thus when Mike walks off-frame and is heard saying something, the camera instinctually starts panning to the left to follow him, to follow where the action seems to be heading. Yet since Beth is the one that resumes control of the conversation, the camera movement ends up appearing somewhat misplaced, even if very present in the moment.

In lieu of Bazin's favored deep focus compositions and long takes, Coherence seems to introduce fluidity to the action through racking focus and pans. These are some of the main means 
of the film's realist aesthetic. With focus racks, the film is able to discreetly direct attention from one subject to another and suggest meaningful connections without sacrificing temporal continuity. Panning the handheld camera, in turn, maps out continuous spatial relations and accommodates the actors' unplanned movement. Regardless, it is evident that neither device promotes the type of increased mental activity on the viewer's part which Bazin championed. Both involve markedly more guiding of the viewer's attention than the Bazinian ideal. Yet it is a guidance born out of reactiveness and of presence. Here, the handheld camerawork and close-up framings prove themselves essential to the film's realist aesthetic. The chronically unsteady image acts as a constant reminder of the camera's presence in a physical space of some kind. Close-ups, on the other hand, denote the camera's proximity to the action within that space. The handheld camera in particular consistently flavors the aforementioned camera manipulations which attempt to introduce continuity to the proceedings. In the discussed cases of pans and racks, the camera strives to follow a conversation and to react to its flow. This reacting to the moment is felt even more when the film's central science-fiction mystery starts to unfurl, leaving the alert camera still at the mercy of the unaware and improvising actors. In my view, it is this pronounced situating of the camera in the space being filmed and amid the action which - regardless of the degree of viewer guidance - results in a palpable realist aesthetic.

\section{CINEMATIC DYNAMICS AND STORYWORLD}

In the previous section, I suggested that Coherence's realist aesthetic is "felt more" as the story progresses. I say "felt more" because, along with the aesthetic, Coherence's realism involves the viewer experiencing the film. The aesthetic is responsible only in part as to why the film could be seen as dealing in realism. The mode of presentation must naturally be collated with what is being presented. The ensuing, entangled interplay of form and narrative content must subsequently be processed by a viewer in order to understand, how Coherence relates to realism and what the functions of the aesthetic are in this relationship. Discussion of the viewer's processing requires terminology derived from cognitive psychology. Accordingly, the aim of this section is to introduce the key cognitive terms used in this paper and thus lay the foundation for an analysis of Coherence's narrative structure which will follow.

As a means of processing the information presented by a film, the viewer constructs cognitive frames. Frames are knowledge structures that are used to understand all types of everyday actions and situations. Their main goal is to explain whatever phenomena at hand as efficiently as possible. David Bordwell associates frames as being "organized, selective, and simplified bodies of knowledge" (Bordwell 136). Frames are simplified in the sense that they consist of a bedrock of knowledge, a basic understanding of a phenomenon. This basic understanding can be elaborated on by gathering new information in a concrete situation (136). In gathering new information about a phenomenon, frames prove themselves organized and selective. In varying degrees, some information is classified as relevant to the frame, while other is relegated to low importance (136) or even discarded. By gathering incoming information and constructing hypotheses around it, frames continuously test their own relevance in explaining a phenomenon - they strive to sustain themselves, but at times they fail and are replaced (Jahn 448). 
With regards to fiction, frames and hypotheses are commonly constructed around questions such as "What is happening? What is the state of affairs? What is the situation?" (Perry 43). Extensive application of frames to fiction is done by Menakhem Perry in his pioneering 1979 essay "Literary Dynamics: How the Order of a Text Creates Its Meanings." Perry begins the essay with a defining statement for his theory of literary dynamics:

The ordering and distribution of the elements in a text may exercise considerable influence on the nature, not only of the reading process, but of the resultant whole as well: a rearrangement of components may result in the activation of alternative potentialities in them and in the structuring of a recognizably different whole. (Perry 35; italics original)

By referring to elements and components, Perry means the successive verbal elements of a literary text, and also semantic complexes (scenes, characters, plot etc.) (35). The latter are built up in a similarly cumulative fashion with any type of fictional text and are thus easily transferrable to discussion of film. Hence I make the distinction of cinematic dynamics, the study of element distribution in a filmic text and the hypotheses/frames evoked by the distribution. Here, I take what Perry regards as "the reading process" to largely correspond with what Bordwell would deem as acts of comprehension. These acts include constructing a spatiotemporal world on the basis of the narrative as well as assigning more explicit meanings to the story (Bordwell 8-9). In this light, the reading process implies the step-by-step construction of such elements. Perry's distinction of "the resultant whole," then, would introduce interpretation in addition to the process of comprehension. In Bordwell's terms, interpretation denotes the construction of implicit and veiled meanings (9). While Perry's method spans both modes of making meaning, this paper limits itself mostly to matters of comprehending Coherence.

Frames figure into the discussion as Perry develops further his system for investigating the order of textual elements. He outlines two possible ways of justifying the structure of a text and the placement of elements in that structure: model-oriented motivation and reader-oriented motivation (Perry 36). The former approach seeks to identify the frames of a given text, whereas the latter is interested in the reader's process of forming them (42). As Perry mainly focuses on the reader and his/her cognitive processes in his analysis of William Faulkner's "A Rose for Emily," so does this paper concern itself with the viewer. The underlying assumption is that the filmic text, Coherence, strives to guide the viewing process to "desirable directions" (40). In other words, the viewer is prompted to form some frames more so than others. By constructing the frames and related hypotheses, the viewer seeks to effectively explain in his mind various narrative phenomena like, for instance, the diegetic reality - the presented fictional world and the focus of this study. My contention is that Coherence guides its viewer, in particular, towards actively forming frames for the diegetic reality.

The following section of this paper, then, begins a viewer-oriented cognitive analysis of Coherence's narrative structure, borrowing some from Perry's method of literary dynamics and shaping it into a cinematic one. More precisely, what will be examined in the analysis are the events that define and challenge the storyworld. Storyworld is characterized by David Herman as an interpreter's "attempt to reconstruct not just what happened but also the surrounding context 
or environment [of a narrative]" (Herman 569-570). Thus what is reconstructed is in essence the diegetic reality, an understanding of it. Compared to a cognitive frame by Herman, a storyworld is constructed by gathering information on characters and settings, their attributes, and relevant actions and events (569-570). Accordingly, in the following, storyworld is seen as corresponding with the viewer's "frame for the diegetic reality." Storyworld is thus a concept more rooted in cognition than the diegetic reality, which makes it a remarkably useful shorthand in the analysis to follow. The umbrella concern of the narrative analysis is to discover, how Coherence prompts a shift in the storyworld the viewer constructs. This interest splits into three specific strands of discussion and eventual argument, which this paper will interweave. They are: (1) What is the nature of the frame system used to negotiate the shift in storyworld? Different frame systems will be elaborated on as the analysis progresses. (2) What are the various functions of the realist aesthetic in storyworld construction? (3) To a much lesser extent, what is the relevant patterning for the events that define the storyworld in Coherence's narrative structure? The instigating influence for the events, and for the storyworld shift which I take as a given, are the parallel universes that slowly emerge in the course of the film.

The analysis presupposes making observations about film style that necessarily exceed in amount those possibly made during a regular viewing process. In light of this stipulation and as a final note before advancing to the analysis, it is best to clarify how the term "viewer" is used in the context of this paper. Here, the term does not denote any particular person or an ideal viewer that covers all of the possible interpretive bases of a film. Rather, the viewer is a construct established for and by the particulars of this research; its constructed nature is already apparent in my limiting of the examined cognitive processes to matters of storyworld. Thus, in the context of this paper, the viewer is a less-than-objective platform from which to argue about viewership in general. In analyzing the events that are the most likely and generic points of storyworld revision for Coherence's viewer, my approach most closely evokes the concept of the general reader defended by Manfred Jahn in his discussion of James Joyce's "Eveline" (Jahn 461-464). Unfortunately, the general reader/viewer construct, while considerate of cognitive resources, is prone to not noting certain textual qualities (Mäkelä 37) like, say, the presence of focus racking. This can be a harmful and regressive assumption by the researcher which I hope to mend in part by suggesting that the viewer of Coherence is still affected by stylistic guidance, even if he/she does not consciously mark it at all times. Thus, when the influence of the film's aesthetic on the viewer is unpacked through the unnatural practice of close watching, it is in service of constructing a relevant and hopefully revealing viewing process.

\section{OPENING PUSH: REALITY FRAME AND AESTHETIC DISRUPTION}

In "Literary Dynamics," Perry suggests that the tension involved with reconciling the initial stages with the later stages of a text is usually present from the start (Perry 57). So it is with the opening scene of Coherence. The scene features the character Emily on the phone with her boyfriend, Kevin, and driving towards the house where the pivotal dinner party will be held. In the two extreme close-ups comprising the scene, Emily oscillates in and out of both focus and the left side of the image. Oscillation is also apparent in the poor signal reception on Emily's phone. Once Emily is finally shot firmly in focus, her phone completely loses its signal. Then suddenly, 
the screen of the phone cracks out of nowhere. The screen cracking is the very first inexplicable event in the world of the film, the first mystifying incident. Yet the event and the scene are presented with the realist camerawork already in place. The prevalent focus racks and out-offrame handheld compositions suggest an active adjustment to the ebbs and flows of Emily's phone call. Similarly reactive is the pan which forsakes Emily in favor of introducing the cracked screen. While more information is needed to process the event in a discrete frame, its reverberations are still felt later on in the viewing process. It acts as a key piece of contradictory data - an initial hint of the supernatural - once the storyworld is better established after the first few scenes. It is presently striking that the incident breaks up the characters having a rather ordinary conversation and thus acts as an intrusion of a kind. This is the central tension that comes to define the film, the ordinary intruded by the inexplicable.

The next event to foster this tension directly recalls the opening scene. Emily is alone in believing that her phone breaking might have something to do with a comet that is scheduled to pass Earth that night. It is only after a quarter-hour into the film and after the dinner party is well underway that she gets an ally. Another character, Hugh, discovers his phone is similarly splintered in the middle. In the scene with Hugh, the previously outlined visual style is again quite consistent, with unstable camera manipulations tracking the characters' puzzled reactions. Sparked by the scene, hypotheses about the connection between the comet and the phones breaking may be constructed by the viewer, even if most of the characters still laugh off the idea. Such hypotheses imply a previously unsuspected supernatural quality to the diegetic reality. But even with two phones inexplicably broken, the storyworld is not yet disturbed enough to make its construction a conscious priority for the viewer. Still at this point, the understanding of the diegetic reality is assumed under a rather automated frame, which is shaped by information the viewer supplies from prior experience. This experience is not per se related to the film itself, but rather draws heavily on the material reality as well as other artworks and films (Perry 45). That said, the realist aesthetic does also inform the frame. The realist camera has so far been content simply to observe and to react alongside the characters as mysterious occurrences emerge. Doing so, the aesthetic avoids drawing attention to itself, and thus the viewer may passively consider the diegetic reality unmanipulated.

After approximately 25 minutes into Coherence, the viewer is first pushed to seriously assess the diegetic reality. Following the scene with Hugh's phone, the lights go out throughout the neighborhood of the dinner party, except for one house. Hugh and another character, Amir, subsequently decide to go to the house to use their phone, seeing as phone service is down as well. They return dazed with Hugh brandishing a bizarre account of what he saw: the exact same dining room which the characters currently inhabit. Hugh is quickly called a liar and also accused of an earlier disturbance, namely, banging on a side door. Hugh's follow-up plan is to write a polite note and deliver it to the other house. Before he can go deliver the note, however, a verbatim copy is posted on the front door of the house where the dinner party is taking place. A shot of the characters realizing the connection between the two notes is the first instance of subjective experience displayed in the film. The shot features most of the characters in medium framing and brought into clarity by sudden racking of focus. The camera trembles forcibly and there is a tense zoom-in before the shot cuts to black. Together these devices serve a function of both conveying 
the characters' shock and rousing the same in the viewer. The presentation is still reactive certainly, but it also reflects character psychology in a so far unseen way. Due to the little-used devices and the implied subjectivity, the shot is the clearest break in the film's aesthetic until now. The break is made more prominent by the familiar mode of reactive, non-subjective presentation quickly resuming afterwards.

The scene evokes various hypotheses. Since all of the primary characters are present in the dining room when the note is posted, a likely hypothesis is that someone outside the group of eight is behind the different disturbances. Another possibility is that a group member is somehow indirectly involved. This notion leads easily to Hugh as he first posits that something truly inexplicable, threatening even, is happening with his story. Also contributing to said hypothesis is Hugh's absence during the banging on the door - then again, a similar fact would incriminate Amir as well. A hypothesis flirting with the supernatural is that somehow Hugh himself, possibly another Hugh from the replica house he reportedly saw, posted the note. The same assumption does not seem acceptable for the characters to speculate about out loud until, in a later scene once the tense situation has defused itself, Mike suggests they go see the house again, "I'm gonna go over there and, theoretically, let's go see if our theoretical selves are there." Much along the lines of Mike's hedging, the hypothesis of parallel characters/universes is very tentative for the viewer at this point as well.

The emergence of the supernatural hypothesis is integral in making the viewer aware of the process of storyworld construction. The hypothesis contradicts much of what has been taken as a given about the diegetic reality so far. In fact, I argue that, primarily based on this scene, the viewer actively constructs a "reality frame" for the storyworld. An initial echo of the larger cognitive shift about to happen, this is done to help explain the most amount of data conveyed about the diegetic reality so far. The frame is retooled from the previously automated understanding that Coherence's reality largely resembles the material reality. Newly awakened, the reality frame is deemed strong enough to account for the present scene's information, even the extremely inexplicable data of the two notes and the replica house.

In a word, the reality frame asserts what Manfred Jahn would describe as its primacy, which refers to the phenomenon of a cognitive frame trying to "retain [itself] for as long as possible" (Jahn 457). A frame that has primacy, a primary frame, tries to explain as much incoming data as it can and stay relevant in explaining the data it already does. It tries to "maximize its scope" (457). Primacy is, alongside recency which will be discussed later, one half of Jahn's preference rule system for frames. The preference rule system assumes that one frame is always dominant in accounting for received data, as opposed to multiple frames governing concurrently. In an effort to preserve itself, the dominant frame may even accommodate minor contradictory data when faced with unfamiliar situations (457). What contradicts the storyworld constructed for Coherence is the implication that there are impossibly two incarnations of the character Hugh. The reality frame thus prefers the non-supernatural hypotheses of outside influence and/or Hugh conspiring to preserve its primacy. Yet, as the characters are slowly starting to believe in the supernatural, the opposing hypothesis of parallel characters is provided with some more credibility in the viewer's eyes. As will be seen, this tension of the real and the supernatural, the 
ordinary and the inexplicable, is exacerbated as the narrative progresses. The following two sections will take a look at how the viewer's frame processing handles the tension and an increasing amount of contradictory data.

At this point, what additionally challenges the notion of a reality-based storyworld is the disruption in the realist aesthetic. This is because, via the disruption, manipulation of the diegetic reality through camera effects becomes more apparent. Based on the discussed shot, the viewer may deduce that the reality Coherence presents is in fact more illusory and affected than previously thought. Even without overt alertness to every presentational detail, the shot still acts as a recognizably heightened and intensely felt moment of revelation for the viewer - a clear departure in the narrative. The break in aesthetic is thus an essential part of the opening push to examine the diegetic reality with a new awareness and scrutiny. But as indicated earlier, the break is very brief. The original mode of presentation returns immediately and stays more or less consistent for the rest of the film. However, I argue that following this scene the function of the realist aesthetic starts to morph. I propose that the aesthetic switches from being a subtle enforcer of the initial storyworld to acting as a resistant foil to the eventual storyworld shift. For the viewer, the aesthetic's unwillingness to adapt to the supernatural mystery produces engaging ambiguity. The new resistant function and its effects will be explored further in the next section.

\section{ENGAGEMENT BY WAY OF AMBIGUITY}

The storyworld constructed for Coherence is truly challenged when Mike's suggestion to go see the other house is undertaken by Mike, Emily, Kevin, and a fourth character, Laurie. Once already on the way back, mirrored on the opposite side of the street, the group is confronted with what appears to be themselves - four figures differentiated only by the color of their glow sticks, red instead of the established blue. There is a prolonged moment of shock during which the film's presentation consists of rapid shots which approximate the vantage point of the original four, thus utilizing point-of-view shots. In between these shots, there are brief close-ups that color in the alarmed reactions of the group. In the shot that introduces the other group, the desired point of view is implied through framing the "others" in a long shot, physically in full view. The long shot is used to convey a physical distance between the two groups - the camera stays with the original characters and shows the others as being "far away." The shot is defined by its profound lack of lighting. Crucially, the faces of the others are not distinct in the darkness of the street. They are recognizable as the familiar characters mostly through certain articles of clothing as well as the glow sticks.

As the shock lingers, there are two more point-of-view shots. In both shots, the distance of the camera to the other group is greater than before and the level of visual detail is further reduced. The shots do not completely assume the subjective perception of the original characters, which point-of-view shots often do, but rather the camera is placed beside the characters. The camera's spatial positioning is indicated by the back of Emily's head, which is visible, but blurred on the left side of the image. Throughout the scene, the point of view of the others is never assumed. As per its realist presence in the filming space, the camera opts instead to remain nearby the originals, show their reactions and experience with them. It is my contention that the realist 
aesthetic is used here in service of instilling ambiguity: The first shot, despite its scant lighting, conveys quite clearly the idea that these are the same characters, yet different incarnations. This is new information to both the original characters and the viewer, the first time coming into contact with suspected doppelgängers. However, the shots that follow let that impression erode somewhat by presenting only vague point-of-view glimpses. By remaining with the original characters, the realist camerawork denies both a closer look at the others and their point of view, thus making the confirmation of their presence impossible.

Processing the scene, the earlier hypothesis that somehow parallel characters and/or worlds are colliding becomes relevant again. Yet the hypothesis cannot be constructed with full certainty because of the pointed ambiguousness of the scene's presentation. At this junction, Marina Grishakova's proposed frame system proves useful. In analyzing modernist and postmodernist works of fiction with similarly unfurling premises as Coherence's, Grishakova suggests that an initial understanding of a textual universe may be challenged by an emerging, opposing subworld. The term "subworld" is more or less synonymous with cognitive frame, which I will use henceforth in discussing Grishakova's ideas. Rather than subscribing to Jahn's system of one dominant frame, Grishakova proposes a multi-tracking system which would allow for competing frames to fluently co-exist (Grishakova 191). She asserts that such fluency can "free up additional cognitive resources" (191). By this she means that more data can be processed and made relevant in reading/viewing - specifically, data which would normally be inconsistent with a single primary frame (191). Seeing characters who are of exact likeness with already known characters is inconsistent with the reality frame established for Coherence. The information is inconsistent with the frame, because the frame is largely based on experience of the material reality. Knowing perfect physical copies of human beings cannot be produced in the material reality, the appearance of the doppelgängers is made unaccountable for the viewer. However, the information of parallel characters can be motivated with a wholly new frame - a conflicting "supernatural frame." In this case, the reality frame need not be discarded even if the supernatural frame is introduced to storyworld construction. This division in frames recalls the characters trying to solve the mystery of the parallel universes following the run-in on the street. Contributing to the designation of the film as science-fiction, the characters speculate about "decoherence" - a term used in quantum physics to refer to two possible realities existing simultaneously. "Coherence," in turn, would imply the separate realities collapsing into one which I suggest will more or less happen with the viewer's frames for the diegetic reality. Still, at this point, the two frames can coincide and compete for "maximal relevancy" (Perry 43) in storyworld construction. Thus my formulation both adopts and goes against Grishakova's: several conflicting frames are allowed, but one always retains an upper hand, primacy. This distinction will be expanded on in the last section.

The discussed four events that define the storyworld (Emily's phone breaking, Hugh' phone breaking, the note being posted, and the group of four meeting their counterparts) all serve as mystifying intrusions into the characters' otherwise normal existence - the key tension of Coherence. With the amount of analyzed events, this tension can be extended to form structural patterns in the narrative. Starting from the beginning, the phone incidents are first to indicate that the diegetic reality is somehow off. The incidents act as small intrusions and are easily 
explained away. They are motivated retroactively once the supernatural frame is formed. By being the first events of their kind, they help define the eventual storyworld frame, even if they do not challenge the initial one. The events that truly challenge the storyworld, in turn, are the ones involving parallel characters in some way. With these events, the intrusion pattern seems to pertain to the proximity and visibility of the implied characters. First, a parallel Hugh is not seen but assumedly posts a note; his presence is demarcated only by a door. Second, some of the characters run into "themselves" on the street. This time the parallel characters are seen, but they are only visible from a distance and in the dark of the nighttime. The presence of the other incarnations seemingly becomes more uncontested with each event. Sketching these patterns helps illustrate how Coherence plays with the viewer's cognitive processing. Based on all the events so far, the film appears to be feeding more and more assuring data about supernatural phenomena as it progresses. At the same time, it avoids providing anything truly conclusive about the diegetic reality, choosing instead to present events with enough ambiguity. This act of withholding keeps the viewer wondering and actively trying to construct the most apt storyworld frame.

The pattern of proximity is continued by a narrative event which, in my view concludes the gradual storyworld shift from the real to the supernatural. The first four analyzed events occur at roughly ten minute intervals, with the run-in on the street taking place close to 35 minutes into Coherence's running time. The conclusive event, then, takes place much closer to the end, well over an hour into the film. In the meanwhile, minor cues pointing towards a supernatural storyworld are presented. Still, during the wait, the narrative structure's main goal is to let uncertainty about the diegetic reality build. Two separate storyworld frames are needed, but the reality frame continues to hold a slight upper hand. The event that strips the frame of its primacy involves the character Mike getting violently beaten by an incarnation of himself. The other Mike breaks into the main house and simply attacks, presumably in an effort to avoid a similar fate. The violent confrontation is carried out quickly in only a few shots. These shots display some of the trademarks of the film, including out of focus close-ups and haphazardly reactive camera movement. The effect of the presentation is such that the viewer cannot make out the distinct features of the two Mikes simultaneously. Rather, the two are recognizable intermittently. This leaves some doubt in the viewer's mind as to how to explain the scene, but only some. Regardless, I argue the unprecedented physical proximity of a parallel character is decisive enough for the viewer to start favoring the supernatural frame.

Disregarding its slight ambiguity, the scene's presentation still has much to do with the storyworld frame changing. Coherence's overall presentation is, to a great extent, made possible by shooting with very mobile digital cameras (Lattanzio). Crucially, the scene at hand shuns digital postproduction in favor of practical effects, namely, a body double of Mike. In the introduction to Realism and Audiovisual Media (2009), Cecília Mello and Lúcia Nagib refer to arguments that the rise of digital film production has been at the expense of André Bazin's ideas of realism (Mello and Nagib xx). Bazin's realism is often associated with indexicality in photography - the notion that an image is in a direct relationship with its referent, the actual object represented. This relationship implies an inherent truthfulness and realism to the image or film. The aforementioned criticism targets the ability to digitally produce film without relying on an actual 
referent in the material reality, leading to lesser realism. Mello and Nagib counter this notion, saying that Bazin himself considered each new technological innovation to actually reinforce realism (xx). For its part, Coherence seems somewhat undecided on its stance on digital. Its realist aesthetic owes some to the introduction of digital shooting technology - light, high-resolution cameras which can be moved freely among the action. Then again, in the scene of Mike getting beaten, the film goes to lengths to retain a physical referent in the form of the body double. At a time when digital manipulation in science-fiction film is a given, Coherence defies expectations and enhances its presentation in a much simpler way. Besides most likely for budgetary reasons (Lattanzio), I would argue the practical effect of the body double is used to shock the viewer into revising the storyworld. As in the scene on the street, the presence of a parallel character clashes with the reality frame; it is a brazen physical impossibility. Yet this time there is much less ambiguity in the presence. It clashes harder due to the proximity and recognizability of the other Mike. Even so, the parallel character is still presented as if occurring like anything else in the diegetic reality, with realist means. When the other Mike enters the house, the camera reacts to an actual presence in the filming space instead of a digital reproduction. This distinction is discernable and felt. Seeing the governing storyworld frame so directly contradicted, the viewer is compelled to abandon it and promote a new one, i.e. the supernatural frame.

Despite its consistent aesthetic, Coherence is not a traditional realist film for certain obvious reasons. With a story featuring parallel characters from parallel universes, it can hardly be labeled a "direct and truthful view of the real world" (Konigsberg 285; Hayward 298). The film does not particularly strive to address social issues either, as it is much too intent on developing its mystery narrative. However, Coherence does involve itself intimately with a realist aesthetic and thus, in its own way, with realism. At its heart, realism is a mode evoked by a film and ultimately constructed by a viewer. It is not tied to any one use or goal of representation. In fact, I take Coherence's realist aesthetic to be a means to the greater end of engaging the viewer in storyworld construction. Throughout the film, the aesthetic argued here remains much the same. Familiar close-ups, handheld pans, and focus racks are used to suggest an exceedingly reactive camera presence in the filming space. Even with this consistency, the realist aesthetic complicates storyworld construction in multiple ways during Coherence's running time. Early in the film, the aesthetic acts as subdued enforcer of a storyworld based on material reality. The effect on the viewer is a lulling one, before anything truly supernatural has occurred in the narrative. This initial, understated function makes it all the more engrossing when something supernatural does eventually happen. Similarly exhilarating is when the aesthetic is briefly disrupted (the scene with the note), which has an indirect function of making the viewer aware of storyworld construction. Later supernatural events are presented as ambiguous, so as to force the viewer to seek resolution for the storyworld more actively. In my view, instigating this kind of cognitive activity is Coherence's most primary objective; it is the reason why "viewer engagement" is so necessary in discussing the film. Finally, in the last analyzed event, the aesthetic is jarring in its consistency to the degree that the viewer changes storyworld frames. Thus in part, the presentation helps prompt a fundamental change in the understanding of the diegetic reality. Throughout all the events, the realist aesthetic is an even plane. Against it, the curvature of storyworld distortion becomes more 
apparent and more intensely felt. A regular mirror, when contoured right, makes for a funhouse one.

\section{FLEXIBLE ENOUGH FRAME SYSTEM}

The supernatural frame gaining primacy at the end of Coherence means that the concurrent frames assumed from Grishakova cease their competition to a great extent. The effect of a frame gaining primacy over another is, in Jahn's preference rule terms, recency. Recency occurs when data that is contrary to a governing frame's essence becomes undeniable. The effect then is to replace the frame with a more pertinent one (Jahn 457). In her dismissal of primacy and recency, Grishakova speaks of the cognitive load of fiction being at times too complicated for such a twopart system to process (Grishakova 191). In the same breath, Grishakova champions her multitrack system of frames for its ability to "recuperate inconsistencies" (191). In her view, preferring single primary frames produces cognitive entropy when sustained, because data which is inconsistent with the frame is too often dismissed (197). Grishakova's language of cognitive entropy and data recuperation suggests a value of dynamism in narrative comprehension for its own sake. A film like Coherence furnishes the potential for dynamically constructing coinciding frames, but ultimately its storyworld is not best defined with such division. The preceding analysis of Coherence indicated a gradual but definite revelation of the supernatural. With a processing system which attempts to motivate as much data as possible, like Grishakova's, one easily loses sight of what a given work of fiction is predominantly striving to accomplish vis-à-vis its comprehension. Coherence's viewer is guided towards experiencing an immense and elongated shift in storyworld frames - an engaging recency effect.

This designation of recency does not change the fact that Grishakova's co-existing frames are a useful tool for cognitive analysis of narrative. Even with Coherence, there is clearly a need for stretches of very dynamic processing, when it is unclear what the exact parameters of the diegetic reality are. It is precisely in this type of micro-level examination, analyzing narrative data piece by piece, that the flexible multi-track system proves beneficial. Jahn's concepts of primacy and recency, in turn, fare better describing major, macro-level cognitive shifts. Yet I see no great barrier to reconciling Jahn's preference rules and Grishakova's multi-tracking. Jahn's theory does preclude two frames governing concurrently, but it is also open to flexibility within the frame system it proposes. The proposed system may indeed gather multiple "related, similar, or partially identical" (Jahn 447) frames together. It does this to account for possible variation in a narrative situation, while continuing to hold one of the frames as the stable primary one (447-448). I submit my middle ground for the two frame systems: When comprehending and constructing some basic element of a narrative, such as the diegetic reality, one cognitive frame must always remain dominant to a degree. It must retain primacy, even if slightly. At the same time, however, cognitive processing must accommodate other frames as well, if deemed necessary based on the narrative information. This includes competing and conflicting frames, not merely similar ones. One of these other frames may eventually replace the dominant frame and thus have recency occur - again, if the narrative occasions it. 
There needs to be, for the sake of dynamic enough comprehension, room for multiple competing frames - but why is a dominant frame required at all times? Jahn clarifies the issue when he justifies the general function of frame replacement, "[A] recency effect... provides a better (more consistent, more natural, less contrived) interpretation of the foregoing as well as the ensuing data" (457). The single primary frame thus vitally structures the meaning-making process by gearing it towards truly relevant information, past or future. Jahn does not make the same distinction Bordwell does between comprehension and interpretation, but here he still offers an insight as to why the two frame systems need negotiation. The same insight can be extended to the matter of why discussion of comprehension processes is necessary in the first place. It is because comprehension via cognitive frames forms a basis for the interpretation and valorization of a given film or narrative. Agreement in the basics of comprehension grounds the eventual discussion between differing interpretations, keeps it from travelling down paths of irrelevance. Comprehension discourse is empowered in such a way by being able to discuss film viewing before viewer-specific factors have figured in too greatly (Bacon 48). Although admittedly, narrative comprehension cannot be fully naturalized in cognitive terms. In Coherence's case, interpretation is guided by the film's undeniable interest in complicating storyworld processing. Indeed, Coherence's priorities are clear: It is first and foremost a funhouse of a narrative film, where information about the nature of the diegetic reality is fed enticingly and intermittently. It more or less shuns other common objectives film may have, such as cultural critique, overt political contextualization, or even the presentation of psychological depth. To its benefit, Coherence focuses rather on providing an engaging viewing experience, spent constructing enthused hypotheses about its diegetic reality. Any and all interpretations of the film must reflect and respect this goal of comprehension to assert their relevance.

\section{CONCLUSION}

This paper has involved itself in great extent with James Ward Byrkit's Coherence. Analysis of the film produced two main assertions: It was argued that realism is a mode to be utilized without preconceptions. It may even extend to films with storytelling ambitions reaching beyond the material reality and without glaring social or political motivations. These stipulations stem from and are illustrated by Coherence, a sci-fi mystery with a defining interest in narrative games. For its part, the film employs a distinct realist aesthetic to influence storyworld construction and engross the viewer. Thus, in its own way, Coherence's realism does in fact strive to "heighten... consciousness" (Konigsberg 285), but about the fictional world at hand rather than the real one. My hope is that, in future research, the category of realism could be more fearlessly subjected to as improbable films as Coherence.

The more theory-minded assertion concerns frame systems, as upheld by the viewer's cognition and applied here to Coherence's storyworld. Derived equally from Manfred Jahn and Marina Grishakova, the frame system I propose favors a dominant frame while allowing multiple conflicting frames to flourish at once - an appropriately flexible intermediate. The system skirts unnecessary dynamism in cognitive processing and is respectful of the comprehension needs of a narrative. The assertion, and the discussion of narrative comprehension in general, seek to avoid too associative readings - ones too removed from a basic manner of constructing film. Such 
interpretation simply cannot be afforded, as discussing film would bleed relevant meaning and vital precision in consequence.

\section{REFERENCES}

Bazin, André. 1967. What is Cinema? Vol. 1. Berkeley and Los Angeles: University of California Press, 2005. Print.

---. André Bazin and Italian Neorealism. Ed. Bert Cardullo. New York and London: Continuum International Publishing Group, 2011. Print.

Bordwell, David. Narration in the Fiction Film. Madison: University of Wisconsin Press, 1985. Print.

---. Making Meaning. Inference and Rhetoric in the Interpretation of Cinema. Cambridge: Harvard University Press, 1991. Print.

Chatman, Seymour. "What Novels Can Do That Films Can’t (and Vice Versa)." Critical Inquiry 7.1 (Autumn 1980): 121-140. Print.

Coherence. Dir. James Ward Byrkit. Bellanova Films and Ugly Duckling Films, 2013. Film.

Grishakova, Marina. "Beyond the Frame: Cognitive Science, Common Sense and Fiction." Narrative 17.2 (May 2009): 188-199. Print.

Herman, David. "Storyworld." Routledge Encyclopedia of Narrative Theory. Eds. David Herman, Manfred Jahn, and Marie-Laure Ryan. Routledge, 2005. 569-570. Print.

Jahn, Manfred. "Frames, Preferences, and the Reading of Third-Person Narratives. Towards a Cogntive Narratology.” Poetics Today 18.4 (Winter 1997): 441-468. Print.

Lattanzio, Ryan. "How Gotham Nominee James Ward Byrkit Made 'Coherence' in 5 Days with No Script or Budget.” Indiewire. SnagFilms, 23 October 2014. Web. 26 December 2014.

Mello, Cecília, and Lúcia Nagib. Introduction. Realism and the Audiovisual Media. By Mello and Nagib. Basingstoke and New York: Palgrave Macmillan, 2009. xiv-xxvi. Print.

Mäkelä, Maria. Uskoton mieli ja tekstuaaliset petokset. Kirjallisen tajunnankuvauksen konventiot narratologisena haasteena. Diss. University of Tampere, 2011. Tampere: Tampere University Press, 2011. Print.

Perry, Menakhem. "Literary Dynamics. How the Order of a Text Creates Its Meanings [With an Analysis of Faulkner's 'A Rose for Emily'].” Poetics Today 1.1-2 (Autumn 1979): 35-64, 311-361. Print.

Tobias, Scott. "How James Ward Byrkit Constructed Coherence." The Dissolve. Pitchfork Media Inc., 26 June 2014. Web. 26 December 2014.

Wimsatt Jr., W.K. and Beardsley, M.C.. "The Intentional Fallacy." The Sewanee Review 54.3 (July-September 1946): 468-488. Print. 